\title{
Adhesion of substrate-adherent combinations for early composite repairs: Effect of intermediate adhesive resin application
}

\author{
Özcan, Mutlu ; Kojima, Alberto Noriyuki ; Pekkan, Gurel ; Mesquita, Alfredo Mikail Melo ; Bottino, Marco
} Antonio

DOI: https://doi.org/10.1016/j.ijadhadh.2013.12.018

Posted at the Zurich Open Repository and Archive, University of Zurich ZORA URL: https://doi.org/10.5167/uzh-100656

Journal Article

Originally published at:

Özcan, Mutlu; Kojima, Alberto Noriyuki; Pekkan, Gurel; Mesquita, Alfredo Mikail Melo; Bottino, Marco Antonio (2014). Adhesion of substrate-adherent combinations for early composite repairs: Effect of intermediate adhesive resin application. International Journal of Adhesion and Adhesives, 49:97-102.

DOI: https://doi.org/10.1016/j.ijadhadh.2013.12.018 
Adhesion of substrate-adherent combinations for early composite repairs: Effect of intermediate adhesive resin application

Mutlu Özcan ${ }^{a,}$, Alberto Noriyuki Kojima ${ }^{b}$, Gurel Pekkan ${ }^{c}$, Alfredo Mikail Melo Mesquita ${ }^{b}$ and Marco Antonio Bottino ${ }^{b}$

${ }^{a}$ Dental Materials Unit, University of Zürich, Center for Dental and Oral Medicine, Clinic for Fixed and Removable Prosthodontics and Dental Materials Science, Plattenstrasse 11, CH-8032 Zürich, Switzerland

${ }^{\mathrm{b}}$ Department of Dental Materials and Prosthodonctics, São Paulo State University (UNESP), Dental School of São Jose dos Campos, Praça Melvin Jones 48, Jardim São Dimas 12245-360, São Paulo, Brazil

${ }^{c}$ Department of Prosthodontics, Faculty of Dentistry, Dumlupinar University, Tavsanli Yolu 10. Km., 43270, Kutahya, Turkey; Oral and Dental Health Center, Kutahya, Turkey

Short Title: Adhesion of similar and dissimilar substrate-adherent dental composite combinations

${ }^{*}$ Correspondance to: Prof. Dr. med. dent. Mutlu Özcan, University of Zürich, Dental Materials Unit, Center for Dental and Oral Medicine Clinic for Fixed and Removable Prosthodontics and Dental Materials Science, Plattenstrasse 11, CH-8032, Zürich, Switzerland. Tel: +41-44-63 45600, Fax: +41-44-63 44305. E-mail: mutluozcan@hotmail.com (M. Özcan) 


\section{ABSTRACT}

This study evaluated the effect of intermediate adhesive resin application (IAR) on tensile bond strength (TBS) for early composite repairs in situations where substrate and repair composite bonded together were once of the same kind with the substrate (similar) and once other than the substrate material (dissimilar). Specimens from three types of composites (TPH Spectrum (TPH), Charisma (CHA) and Filtek Z250 (Z250) were fabricated. The specimens in each composite group $(n=72)$ were randomly divided into 6 subgroups $(n=12)$. In each composite group, the similar and two dissimilar composites were bonded onto the substrates once using an IAR (Adper Single Bond Plus) and once without. After water storage for 1 week at $37^{\circ} \mathrm{C}$, substrate-adherent combinations were submitted to tensile test. Data were analyzed with three-way ANOVA and Tukey's tests $(\alpha=0.05)$. The substrate-adherent combination $(p=0.0001)$, adherent (repair) composite $(p=0.0001)$, and application of IAR ( $p=0.0001)$ significantly affected the results. Utilization of IAR improved the repair bond strength for all composite combinations.

Keywords: Composite resin, Dental restoration repair, Repair, Surface conditioning, Tensile bond strength 


\section{Introduction}

Composite resins are routinely used in restorative dentistry due to the improvement in the adhesive systems, polymerization devices and physical and mechanical properties of the resin systems [1-3]. Typically, application of direct composite restorations require minimal or no preparation of the dental tissues. Subsequent to etching and conditioning enamel and/or dentin with adhesive promoters, the clinician applies composite resin using layering technique incrementally. This requires high artistic skills and it is a difficult task to match the colour and form of the restoration with the neighboring tooth. Application of adhesives and composite resins require a dry environment, which is achieved under a rubber dam but this then results in dehydration of the tooth and may yield to colour mismatch with the neighbouring tooth or dental tissues.

Traditionally, direct resin restorations that do not meet the esthetic and functional requirements are replaced [4]. Replacement of restorations is the most common practice in daily clinical routine [5]. In fact, complete removal of restorations with minor defects may be considered as excessively aggressive since this procedure inevitably has the disadvantages of tooth weakening, loss of tooth structure, injury to the pulp tissue [6], longer period of clinical work and higher cost [7-9]. These disadvantages may be minimized by accomplishment of repairs at the areas of failure, instead complete replacement of the restorations [10,11]. The concept of repairs is still not fully acknowledged by most of the dental schools [4,5], even though utilization of surface conditioning methods and adhesive resins may provide $80-90 \%$ of the cohesive strength of resin systems after repair [12-15].

Adhesion between two composite resin layers is achieved in the presence of an oxygen-inhibited layer of unpolymerized resin $[7,16]$. However, controversial opinions exist on the function of oxygeninhibited layer on the adhesion between two composite resin layers [17-19]. Some studies have shown that composite resin layers could bond even in the absence of an oxygen-inhibited layer $[18,19]$ but it is also speculated that the amount of the remaining active, free radicals that is available 
for reacting with resin composite monomers is a crucial factor in direct composite repair [18].

Several surface conditioning methods have been suggested to maximize the repair strength $[1,7,16,20]$. The most commonly used methods are based on air-borne particle abrasion to increase the surface roughness, followed by the application of a silane coupling agent and a low-viscosity intermediate adhesive resin (IAR) $[1,13-15,20]$. Silane coupling agents or IARs improves surface wetting and chemical bonding between the substrate composite and the new composites by activating the inhibition layer [21]. The three possible mechanisms during composite repair with the use of IARs are the chemical bond formation to the matrix, chemical bonds to the exposed filler particles, and micromechanical retention caused by penetration of the monomer components to microcracks in the matrix [21].

Even though the literature presents several comparative studies, there is no consensus to date as to which surface conditioning protocol would deliver optimum repair strength for composite resins [10]. While application of an IAR was reported to activate the interpenetrating polymer network in some studies [1,7], in others physico-chemical activation was found to be compulsory for durable composite-composite adhesion [13,14,22]. Airborne particle abrasion used for physico-chemical surface conditioning not only requires additional armamentarium in the clinical practice adding to the costs but also could impair the adhesion to composites especially in cases when the composite is surrounded by enamel and/or dentin, namely the particles may obstruct the dentin tubuli [23].

One of the clinical problems faced during accomplishment of repair procedures is the knowledge on the composite resin type and brand employed for the particular restoration. Since commercial products present different chemical compositions, the repair strength at the restoration/repair interface may be affected $[8,9,20]$.

The objectives of this study therefore were to evaluate the tensile bond strength (TBS) of similar and dissimilar substrate-adherent composite resin combinations with and without IAR for early composite repairs. The null hypotheses tested were a) similar and dissimilar substrate-adherent 
composite resin combinations would not show difference in repair strength and b) utilization of an IAR would not affect the repair strength.

\section{Experimental}

\subsection{Materials and Methods}

The brands, types, abbreviations, chemical compositions and manufacturers of the composite resins and the adhesive resin used for the experiments are listed in Table 1.

\subsubsection{Specimen preparation}

Composite specimens ( $n=72$ for each group) (TPH Spectrum, Dentsply DeTrey GmbH, Konstanz, Germany; Charisma, Heraeus Kulzer GmbH, Hanau, Germany; Filtek Z250, 3M ESPE AG, Seefeld, Germany) (diameter: $3 \mathrm{~mm}$, height: $5 \mathrm{~mm}$ ), acting as substrate composites, were fabricated incrementally with the aid of machined brass rings as metallic base (Fig. 1a). The thickness of each composite resin layer $(1.66 \mathrm{~mm})$ was standardized using three machined rings with progressive taper and photo-polymerized (Demetron LC, SDS Kerr, Orange, CA, USA) with an irradiance of 600 $\mathrm{mW} / \mathrm{cm}^{2}$ for $20 \mathrm{~s}$. After packing the last increment with a dental spatula, a Mylar strip (KerrHawe SA, Bioggio, Switzerland) was placed over the composite surface and covered with a clear glass plate on the brass mold for removal of excess material and better accommodation and smoothing of the substrate surface. After smoothing, the Mylar strip (KerrHawe SA) and the glass plate was removed before final polymerization in order not to avoid the formation of oxygen inhibition layer $[7,16]$. Mylar strip was removed sliding the strip sideways. This was done at $18^{\circ} \mathrm{C}$ room temperature and with this route pull-back of composite beneath was avoided. At room temperature at $24^{\circ} \mathrm{C}$, and also removing the strip by peeling movement, pull-back was experienced in preliminary tests.

The substrate composite resin surfaces were only water sprayed and air-dried. The specimens in each composite group $(n=72)$ were randomly divided into 6 subgroups $(n=12)$. Half of the specimens in each composite group $(n=36)$ was treated with an IAR (Adper Single Bond Plus, 3M ESPE AG). IAR was applied 2 coats for $15 \mathrm{~s}$ using a microbrush, air-dried for $5 \mathrm{~s}$ and each layer was photo- 
polymerized for $10 \mathrm{~s}$. The other half in each composite group $(n=36)$ did not receive IAR. The specimens were kept in dark in distilled water at $37^{\circ} \mathrm{C}$ for $24 \mathrm{~h}$.

In each composite group (TPH, CHA and Z250), the same composite material and the other two composite materials were acted as adherent (repair) composites and bonded onto the substrate composites. The shade of the adherent was the same with the substrate. A disc-shaped split polyethylene mold with a tapered orifice in its center was used for the application of the adherent composite resin (Fig. 1b). Its narrowest base, allowing an hourglass shaped specimen, joined the two orifices. Each metallic mold, in turn, was connected to one orifice of the disc-shaped polyethylene mold for application of the adherent composite resin. The composite resin was inserted incrementally from the direction of the ring having the smallest orifice to the ring with the largest orifice. Each layer was photo-polymerized for $20 \mathrm{~s}$ until the tapered orifice was completely filled (height: $5 \mathrm{~mm}$ ). Then, by loosening the two lateral screws that joined the two portions of the split disc, the polyethylene mold was opened that allowed removal of the hourglass-shaped specimens (Fig. 1c). The specimens were photo-polymerized for an additional $60 \mathrm{~s}$ (Fig. 1d).

The bonded specimens were stored in distilled water for one week at $37^{\circ} \mathrm{C}$, and then submitted to tensile test.

\subsubsection{TBS test and failure analysis}

Two metal jigs were fabricated to place the specimens in the Universal Testing Machine (EMIC, DL 1000, São José dos, Pinhais, PR, Brazil) (Fig. 2a). Each metallic part was composed of one stainless steel cylindrical piece with a rod for connection to the Universal Testing Machine. Each metallic jig consisted a brass, tapered sleeve (split through its long axis) for placement of the end of the hourglass-shaped specimen (Fig. 2b). At the onset of testing, when the specimen was debonded with the increase in distance between the active arms of the machine, it was kept loosened inside these metallic parts. The sleeves were aligned in such a way that the adhesive interface remained perpendicular to the axis of applied force. The TBS test was performed at a crosshead speed of 1 
$\mathrm{mm} / \mathrm{min}$ with a $50 \mathrm{Kgf}$ load cell (Fig. 2c).

Subsequently, specimens were evaluated visually by two operators and the types of failures were categorized as; Score 1: cohesive failure in the composite substrate, Score 2: adhesive failure at the interface, Score 3: mixed failure.

\subsection{Statistical analysis}

Statistical analysis was performed using SPSS System 11.0 for Windows (SPSS Inc., Chicago, IL, USA). Bond strength data (MPa) were submitted to analysis of variance (3-way ANOVA). Multiple comparisons were made with Tukey`s test $(\alpha=0.05)$.

\section{Results}

Significant effects of the substrate-adherent combination $(p=0.0001)$, adherent (repair) composite $(p=0.0001)$ and application of IAR $(p=0.001)$ were found on the bond strength results (Table 2$)$.

With the use of IAR, mean bond strength (MPa) of similar substrate-adherent combinations was

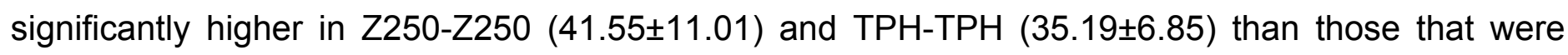
bonded without the use of IAR $(p<0.05)$ (Table 3$)$. TBS values CHA-CHA composite bonded with and without IAR showed no statistically significant difference. Among the similar substrate-adherent

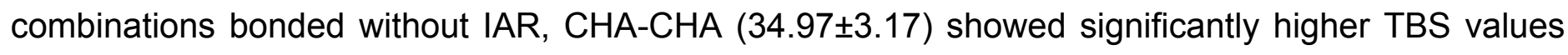
than TPH-TPH $(21.76 \pm 4.74)$ and Z250-Z250 (17.53 \pm 10.21$)$ combinations. Dissimilar substrateadherent combinations, with the use of IAR did not show statistically significant difference $(p>0.05)$. Dissimilar substrate-adherent combination groups, without the use of IAR, revealed statistically

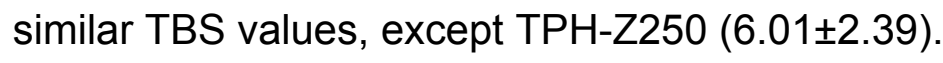

Failure analysis indicated no cohesive failures in the composite substrate (Score 1: 0 out of 216). While IAR applied groups showed exclusively mixed failures (Score 3), the groups without IAR application demonstrated only adhesive failures (Score 2).

\section{Discussion}


Repair or partial replacement of direct composite resin restorations without evidence of clinical or radiographic failure allows preservation of the intact restoration and/or tooth portion that could be considered as an option instead of complete replacement of the restoration $[2,4,5]$. This study was undertaken in order to evaluate the TBS of similar and dissimilar substrate-adherent composite resin combinations with and without IAR for early composite repairs.

The weak link between the substrate composite and the repair composite is the interface between the two materials. Several methods have been recommended to improve the adhesion between prepolymerized composite and repair resin such as micromechanical interlocking by roughening the surface using diamond bur, air-abrasion with alumina particles, tribochemical silica coating, phosphoric or hydrofluoric acid treatments, silane and/or adhesive application $[1,6,8-11,15]$. In this study, no surface conditioning procedures were applied to the substrate surfaces. The results of this study revealed that similar and dissimilar substrate-adherent composite resin combinations significantly affected the bond strength results. Therefore, the first null hypothesis was rejected. The obtained bond strength values were higher than some previous studies [8-10] and comparable with some others $[1,6,14,15]$. Even without any IAR application, since similar composite-adherent combinations delivered higher results (CHA-CHA) than those of dissimilar ones, it may be stated that the lack of knowledge on the composite resin composition and brand puts the success of the repair action in question for clinical situations.

The stresses at the bonded interfaces between a tooth and a restoration could be complex and they can be identified as primarily tensile or shear types of stresses, created by forces working either perpendicular or parallel to the tooth surface. Because it allows homogeneous distribution of stresses and consequently better evaluation of the bond strength [24,25], the tensile test method was used in this study. Microtensile test was not used because sectioning of the specimens in this method may lead to a considerable amount of pre-test failures [26]. Hourglass-shaped specimens were prepared in order to facilitate better adaptation of the specimen to the jigs of the testing machine where adhesive 
interface remained perpendicular to the axis of applied force. Limited information is available in the literature using this test method for measuring repair strength of composites [27].

IAR application increased the bond strength values in most of the simulated composite-composite repair conditions significantly. Therefore, the second part of the null hypothesis that the utilization of an IAR would not affect the repair strength was also rejected. The IAR used was in fact a dentin bonding agent which is easy to apply compared to other conditioning systems that require additional equipment $[28,29]$. The function of IAR is to create a chemical unification with the resin matrix [1]. Some studies have demonstrated that IARs without fillers may increase the bond strength, regardless of the surface conditioning method employed $[13,22]$.

In a previous study, El-Askary et al. [27] investigated the effect of different surface conditioning methods on the immediate repair strength of a microfine hybrid restorative composite with tensile bond test using non-trimmed hourglass-shaped specimens. In contrast to our results, they reported that the application of a thin adhesive layer in one coat did not improve the immediate repair bond strength as the other surface conditioning methods did. In this study, the IAR was applied according to the manufacturer's instruction in two coats. Whether the thickness of the IAR affected the results or not need further investigation. The IAR used in this study contains water/ethanol solvent and it has highlydispersed nanofillers that might have contributed to higher bond strength. It has been previously demonstrated that acetone-based solvent containing IARs are more technique sensitive and did not increase the repair bond strength of composite resins and therefore they were not recommended for intraoral repair [16]. On the other hand, Balkenhol et al. [30] reported that IARs based on bisGMA/TEGDMA with acetone are best suited for conditioning the aged surfaces of temporary crown and bridge materials to enhance bond strength. Since in that study only acetone-based adhesive material was used, further studies were recommended to investigate the effect of other solvents on repair bond strength of composite resins. Moreover, the adhesive used in this study contains both the primer and the adhesive. In the study of Rathke et al. [15], the use of a hydrophilic primer (OptiBond 
FL Prime, Kerr Corp., Orange, CA, USA) and a less hydrophobic primer-adhesive combination (Excite, Ivoclar Vivadent AG), did not produce significantly higher repair bond strengths than the hydrophobic filled adhesive (Optibond FL Adhesive, Kerr Corp.). They concluded that the use of a primer might be limited to clinical situations with exposed dentin at the repair site. When only enamel is involved, the use of an adhesive without primer may be sufficient. Studies looking at composite repairs next to enamel and/or dentin require further investigations.

For durable adhesive joints, not only the conditioning method or the IAR type but also the mechanical properties of the substrate and the adherent composite resin are of importance. In the study of Hamano et al. [10], repair strength of a nanofilled composite resin (Ceram X, Dentsply, Konstanz, Germany) on the same composite material revealed no significant difference with and without application of an IAR (Xeno V, Dentsply). For this reason, they stated that this nanofilled composite resin does not need any type of conditioning as wettability of the material was superior to other highly filled composites. Hence, composites with high viscosity may benefit more from the application of an IAR to increase their wettability on the substrate. In that respect, in this study, microhybrid composite, Z250, benefitted from the IAR application more than the hybrid composite (TPH). Although shear tests show more cohesive failures in the substrate material, in previous studies [13,22], cohesive failures were not observed with IAR application when microfilled composites were repaired, in this study.

Interestingly, when the substrate and adherent were swapped, the bond results were not always similar (e.g. TPH-Z250: 6.01 MPa; Z250-TPH: 16.72 MPa). Although chemically the interface was principally similar, being both methacrylate based composite resins, the difference could be due to the variation in light transmision or polymerization achieved. Z250 contains $82 w t \%$ fillers, whereas TPH has $77 w t \%$ according to the manufacturers` information. Degree of conversion of the materials was not the scope of this study but in case of less wettability of the adherent on the substrate adhesion may be impaired or better polymerization of the adherent, may present more rigidity at the interface yielding to a brittle adhesive joint. This may then result in a quicker crack propagation and eventually lower bond 
strength. Thus, from the clinical point of view, using the same composite resin combinations would be the best practice.

The repair model simulated in this study represents the clinical situation for non-aged substrates, namely the early repairs. This kind of repair is usually encountered when the form of the restoration is not adequate or there is mismatch with the neighboring teeth especially in anterior Class IV or direct composite veneers. Since high clinical skills are required in handling composite resin materials, such early failures could be experienced but they could be repaired through relayering in the subsequent session. The surfaces of the polymeric materials change after being exposed to the oral environment. Hence, the age of the substrate composite should be considered to simulate late composite-composite repair.

The higher activity of residual free radicals in composites may be observed on the substrate surface during the first 24 hours after polymerization [10]. The results of the study of Dall'oca et al. [18] indicated that the presence of an oxygen-inhibited layer does not significantly affect the composite-tocomposite bond strength if coupling is performed within the first 14 days. They speculated that the amount of remaining active free radicals within the nitrogen-cured bonding resin layer that is available for reacting with resin composite monomers is the most important factor for a direct composite repair, even in the absence of oxygen. Storage of specimens in distilled water for one week in this study was based on the fact that saturation by water promotes completion of free radical reactions, softening of the matrix $[12,14,15]$. Even though composite resins are composed of bis-GMA, UDMA, TEGDMA and inorganic matrix, variations in the amount of these components may alter the repair strength. Although the inorganic matrix percentages of the composite resins investigated showed similarities in terms of filler particle type and size, mechanical properties of the composites related to their filler content may still affect the repair strength due to variations in their flexural strength, flexural modulus, hardness, and fracture toughness [31]. Moreover, bis-GMA adduct used in TPH is more hydrophobic than unmodified bis-GMA due to the substitution of two hydroxyl groups [32]. Even though 1 week may be 
considered short, this might have reduced the water sorption and related detrimental effects $[1,33]$. Therefore, the time of repair is important as composite resins degrade over time [10,24,34]. Different substrate composite resin aging periods ranging from immediate to 1 year have been used to age restorations $[10,22,27,28]$. Since the activity of residual free radicals continue to be observed longer time [35], water storage of specimens for several months before testing increases the predictability of the bonding performance of the tested interface. In a recent study where a variety of surface conditioning methods (diamond bur, air-abrasion with alumina particles, silica coating, phosphoric and hydrofluoric acid treatment) were tested for composite repair strength [20] on artificially aged composites no universally applicable repair method could be recommended for all sorts of composite resins. The composite type again affected the results. Future studies should concentrate on identifying the aging affect as it relates to the presence or absence of the oxygen inhibition layer [15], and the most suitable repair method for the specific composite. In order to make it more reliable for repair actions, the type of composite must be recorded in the patient files. In this study, early repair actions were simulated in situation where the colour or the form of the restoration need to be corrected the next day or the session. In such a situation, the substrate composite resin is not exposed to aging. Thus, no long-term water storage or thermocycling were practiced.

In clinical practice, prior to repair actions, usually the top surface of the composite is removed using a bur. The amount of removal is highly operator dependent and difficult to standardize in an in vitro study. This was not done on purpose in this study that could still be seen as a limitation of this study.

In this study, no cohesive failures in the substrate composite were noted indicating that the cohesive strength of the substrate composite was not exceeded. Clinical studies are needed to identify whether application of IAR alone or activating the substrate surface with physico-chemical conditioning media is necessary for durable repairs. 


\section{Conclusions}

Within the limitations of this study, the following conclusions were drawn:

1. Utilization of IAR on the similar substrate-adherent combinations significantly increased the TBS results for Z250-Z250 and TPH-TPH composites $(p<0.05)$ but it did not change the TBS values of CHA-CHA $(p>0.05)$.

2. The use of IAR on the dissimilar substrate-adherent combinations significantly increased the TBS results $(p<0.05)$.

3. When the substrate composites were conditioned with the adhesive resin, failure types changed from adhesive to mixed failures but no cohesive failures in the substrate were experienced in any of the groups. 


\section{References}

[1] A. Tezvergil, L.V. Lassila, P.K. Vallittu, Composite-composite repair bond strength: effect of different adhesion primers, J. Dent. 31 (2003) 521-525.

[2] E.M. Fernández, J.A. Martin, P.A. Angel, I.A. Mjör, V.V. Gordan, G.A. Moncada, Survival rate of sealed, refurbished and repaired defective restorations: 4-year follow-up, Braz. Dent. J. 22 (2011) 134-139.

[3] N. Ilie, R. Hickel, Resin composite restorative materials, Aust. Dent. J. 56 (2011) 59-66.

[4] I.R. Blum, C.D. Lynch, A. Schriever, D. Heidemann, N.H. Wilson, Repair versus replacement of defective composite restorations in dental schools in Germany, Eur. J. Prosthodont. Restor. Dent. 19 (2011) 56-61.

[5] I.R. Blum, A. Schriever, D. Heidemann, I.A. Mjor, N.H. Wilson, The repair of direct composite restorations: an international survey of the teaching of operative techniques and materials, Eur. J. Dent. Educ. 7 (2003) 41-48.

[6] T. Izumi, H. Inoue, H. Matsuura, F. Mukae, H. Ishikawa, H. Hirano, N. Tamura, Age-related changes in the immunoreactivity of the monocyte/macrophage system in rat molar pulp after cavity preparation, Oral Surg. Oral Med. Oral Pathol. Oral Radiol. Endod. 94 (2002) 103-110.

[7] K.J. Soderholm, M.J. Roberts, Variables influencing the repair strength of dental composites, Scand. J. Dent. Res. 99 (1991) 173-180.

[8] M. Rinastiti, M. Özcan, W. Siswomihardjo, H.J. Busscher, Immediate repair bond strengths of microhybrid, nanohybrid and nanofilled composites after different surface treatments, J. Dent. 38 (2010) 29-38.

[9] A. Wiegand, B. Stawarczyk, W. Buchalla, T.T. Tauböck, M. Özcan, T. Attin, Repair of silorane composite-Using the same substrate or a methacrylate-based composite? Dent. Mater. 28 (2012) e19-25. 
[10] E.U. Celik, Z. Ergücü, L.S. Türkün, U.K. Ercan, Tensile bond strength of an aged resin composite repaired with different protocols, J. Adhes. Dent. 13 (2011) 359-366.

[11] A. Saracoglu, M. Özcan, O. Kumbuloglu, M. Turkun, Adhesion of resin composite to hydrofluoric acid-exposed enamel and dentin in repair protocols, Oper. Dent. 36 (2011) 545-553.

[12] B. Pounder, W.A. Gregory, J.M. Powers, Bond strengths of repaired composite resins, Oper. Dent. 12 (1987) 127-131.

[13] C.W. Turner, J.C. Meiers, Repair of an aged, contaminated indirect composite resin with a direct, visible-light-cured composite resin, Oper. Dent. 18 (1993) 187-194.

[14] S.A. Shahdad, J.G. Kennedy, Bond strength of repaired anterior composite resins: an in vitro study, J. Dent. 26 (1998) 685-694.

[15] A. Rathke, Y. Tymina, B. Haller, Effect of different surface treatments on the compositecomposite repair bond strength, Clin. Oral Investig. 13 (2009) 317-323.

[16] N. Hamano, Y.C. Chiang, I. Nyamaa, H. Yamaguchi, S. Ino, R. Hickel, K.H. Kunzelmann, Effect of different surface treatments on the repair strength of a nanofilled resin-based composite, Dent. Mater. J. 30 (2011) 537-545.

[17] F.A. Rueggeberg, D.H. Margeson, The effect of oxygen inhibition on an unfilled/filled composite system. J. Dent. Res. 69 (1990) 1652-1658.

[18] S. Dall'Oca, F. Papacchini, C. Goracci, A.H. Cury, B.I. Suh, F.R. Tay, A. Polimeni, M. Ferrari, Effect of oxygen inhibition on composite repair strength over time. J. Biomed. Mater. Res. B Appl. Biomater. 81 (2007) 493-498.

[19] E.S. Shawkat, A.C. Shortall, O. Addison, W.M. Palin, Oxygen inhibition and incremental layer bond strengths of resin composites. Dent. Mater. 25 (2009) 1338-1346.

[20] B.A. Loomans, M.V. Cardoso, F.J. Roeters, N.J. Opdam, J. De Munck, M.C. Huysmans, B. Van Meerbeek, Is there one optimal repair technique for all composites? Dent. Mater. 27 (2011) 701-709. 
[21] T. Brosh, R. Pilo, N. Bichacho, R. Blutstein, Effect of combinations of surface treatments and bonding agents on the bond strength of repaired composites, J. Prosthet. Dent. 77 (1997) 122-126. [22] J. Brendeke, M. Özcan, Effect of physicochemical aging conditions on the composite-composite repair bond strength, J. Adhes. Dent. 9 (2007) 399-406.

[23] S. Sauro, T.F. Watson, I. Thompson, Dentine desensitization induced by prophylactic and airpolishing procedures: an in vitro dentine permeability and confocal microscopy study, J. Dent. 38 (2010) 411-422.

[24] R. van Noort, S. Noroozi, I.C. Howard, G. Cardew, A critique of bond strength measurements, J. Dent. 17 (1989) 61-67.

[25] A. Della Bona, R. van Noort, Shear vs. tensile bond strength of resin composite bonded to ceramic, J. Dent. Res. 74 (1995) 1591-1596.

[26] M. Özcan, S.H. Barbosa, R.M. Melo, G.A. Galhano, M.A. Bottino, Effect of surface conditioning methods on the microtensile bond strength of resin composite to composite after aging conditions, Dent. Mater. 23 (2007) 1276-1282.

[27] F.S. El-Askary, A.S. Fawzy, H.M. Abd Elmohsen, Tensile bond strength of immediately repaired anterior microfine hybrid restorative composite using nontrimmed hourglass specimens, J. Adhes. Dent. 11 (2009) 41-47.

[28] P. Padipatvuthikul, L.H. Mair, Bonding of composite to water aged composite with surface treatments, Dent. Mater. 23 (2007) 519-525.

[29] T.T. Kallio, T.M. Lastumaki, P.K. Vallittu PK, Bonding of restorative and veneering composite resin to some polymeric composites, Dent. Mater. 17 (2001) 80-86.

[30] M. Balkenhol, K. Michel, J.Stelzig, B. Wöstmann, Repairability of cross-linked biopolymers, J. Dent. Res. 88 (2009) 152-157.

[31] K.H. Kim, J.L. Ong, O. Okuno, The effect of filler loading and morphology on the mechanical properties of contemporary composites, J. Prosthet. Dent. 87 (2002) 642-649. 
[32] C. Huang, F.R. Tay, G.S.P. Cheung, L.H. Kei, S.H.Y. Wei, D.H. Pashley, Hygroscopic expansion of a compomer and a composite on artificial gap reduction, J. Dent. 30 (2002) 11-19.

[33] C.W. Sau, G.S.Y. Oh, H. Koh, C.S. Chee, C.C. Lim, Shear bond strength of repaired composite resins using a hybrid composite resin, Oper. Dent. 24 (1999) 156-161.

[34] M.R. Bouschlicher, J.W. Reinhardt, M.A. Vargas, Surface treatment techniques for resin composite repair, Am. J. Dent. 10 (1997) 279-283.

[35] S.D. Heintze, B. Zimmerli, Relevance of in vitro tests of adhesive and composite dental materials. A review in 3 parts. Part 3: in vitro tests of adhesive systems, Schweiz Monatsschr. Zahnmed. 121 (2011) 1024-1040. 


\section{Captions to tables and figures}

\section{Tables}

Table 1. The brands, types, chemical compositions and manufacturers of the composite resins and the adhesive resin used for the experiments.

Table 2. Results of 3-way analysis of variance for the substrate and adherent composite types, application of intermediate adhesive resin and the interaction terms according to bond strength data $\left({ }^{*} p<0.05\right) .{ }^{*}$ Statistically significant difference at the level of $5 \%$.

Table 3. Mean and ( \pm standard deviation) of TBS data (MPa) based on the substrate-adherent composite resin combinations with or without application of an intermediate adhesive resin for TPH, CHA, Z250 used as substrate (base) composite. Different small superscript letters within each row and capital letters within each column indicates statistically significant differences $(p<0.05)$. For group abbreviations see Table 1 .

\section{Figures}

Figs. 1a-d Photos of a) machined brass ring used as metallic base for the fabrication of substrate composite, b) disc-shaped split polyethylene mold with a tapered orifice in its center used for the application of the adherent composite resins, c) two lateral screws joining the two portions of the split disc, d) hourglass-shaped specimen obtained after removal of the polyethylene mold following photo-polymerization.

Figs. 2a-c Photos of a) two metal jigs with perforated rods fabricated to place the specimens in the Universal Testing Machine, b) disassembled metallic part showing tapered hemi sleeves, cylinder, perforated rod, c) specimen under tensile loading where the sleeves aligned in such a way that the adhesive interface remained perpendicular to the axis of applied force. 


\section{Tables}

Table 1. The brands, types, chemical compositions and manufacturers of the composite resins and the adhesive resin used for the experiments.

\begin{tabular}{|c|c|c|}
\hline $\begin{array}{l}\text { Brand, } \\
\text { resin } \\
\text { Abbreviation }\end{array}$ & Chemical composition & Manufacturer \\
\hline $\begin{array}{l}\text { TPH Spectrum } \\
\text { (Hybrid) } \\
\text { (TPH) } \\
\text { Batch No: } 604190 \mathrm{E}\end{array}$ & $\begin{array}{l}\text { Matrix: bis-GMA adduct, bis-EMA, } \\
\text { TEGDMA } \\
\text { Filler: Ba-Al-B-Si glass (mean particle } \\
\text { size } 1 \mu \mathrm{m} \text {, colloidal silica particle size } \\
0.04 \mu \mathrm{m}) 57 \mathrm{vol} \%, 77 \text { wt } \%\end{array}$ & $\begin{array}{l}\text { Dentsply DeTrey GmbH, } \\
\text { Konstanz, Germany }\end{array}$ \\
\hline $\begin{array}{l}\text { Charisma } \\
\text { (Micro Hybrid) } \\
\text { (CHA) } \\
\text { Batch No: } 010513\end{array}$ & $\begin{array}{l}\text { Matrix: bis-GMA, TEGDMA } \\
\text { Filler: Ba-Al-B-F-Si glass }(0.02-2 \mu \mathrm{m}) \text {, } \\
\text { pyrogenic } \mathrm{SiO}_{2}(0.02-0.07 \mu \mathrm{m}) 61 \\
\text { vol\%, } 78 \text { wt } \%\end{array}$ & $\begin{array}{l}\text { Heraeus Kulzer GmbH, } \\
\text { Hanau, Germany }\end{array}$ \\
\hline $\begin{array}{l}\text { Filtek Z250 } \\
\text { (microhybrid) } \\
\text { (Z250) } \\
\text { Batch No: } \mathrm{n} 14076 \mathrm{Br}\end{array}$ & $\begin{array}{l}\text { Matrix: UDMA, bis-EMA6, TEGDMA } \\
\text { Filler: } \mathrm{ZrO}_{2} / \mathrm{SiO}_{2} \text { (mean particle size } \\
\text { 0.6) } 60 \mathrm{vol} \%, 82 \mathrm{wt} \%\end{array}$ & $\begin{array}{c}\text { 3M ESPE AG, Seefeld, } \\
\text { Germany }\end{array}$ \\
\hline $\begin{array}{l}\text { Adper Single } \\
\text { Bond Plus } \\
\text { (Intermediate } \\
\text { adhesive resin) } \\
\text { (IAR) } \\
\text { Batch No: 340867BR }\end{array}$ & 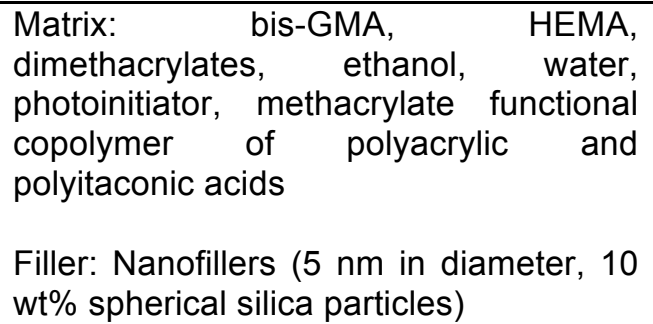 & $\begin{array}{c}\text { 3M ESPE AG, Seefeld, } \\
\text { Germany }\end{array}$ \\
\hline
\end{tabular}

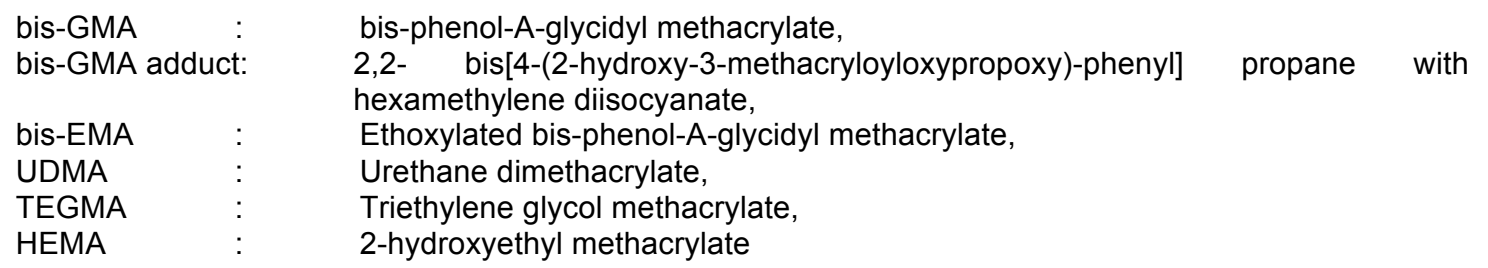


Table 2. Results of 3-way analysis of variance for the substrate and adherent composite types, application of intermediate adhesive resin and the interaction terms according to bond strength data ( $\left.{ }^{*} p<0.05\right)$. ${ }^{*}$ Statistically significant difference at the level of $5 \%$.

\begin{tabular}{|c|c|c|c|c|c|}
\hline Source of variation & DF & SS & MS & $\mathbf{F}$ & $\mathbf{P}$ \\
\hline $\begin{array}{l}\text { Intermediate adhesive } \\
\text { resin (IAR) application }\end{array}$ & 1 & 9608.6 & 9608.58 & 134.38 & $0.0001^{*}$ \\
\hline $\begin{array}{l}\text { Substrate Composite } \\
\text { Type (Base) }\end{array}$ & 2 & 564.5 & 282.25 & 3.95 & $0.0210^{*}$ \\
\hline Adherent Composite & 2 & 1986.5 & 993.25 & 13.89 & $0.0001^{*}$ \\
\hline Type & & & & & \\
\hline IAR*Substrate & 2 & 979.5 & 489.77 & 6.85 & $0.0014^{*}$ \\
\hline IAR*Adherent & 2 & 469.5 & 234.77 & 3.28 & $0.0398^{*}$ \\
\hline Substrate*Adherent & 4 & 3257.0 & 814.25 & 11.39 & $0.0001^{*}$ \\
\hline IAR*Substrate*Adherent & 4 & 763.4 & 190.85 & 2.67 & $0.0338^{*}$ \\
\hline Error & 178 & 12727.5 & 71.50 & & \\
\hline Total & 195 & & & & \\
\hline
\end{tabular}


Table 3. Mean and ( \pm standard deviation) of TBS data (MPa) based on the substrate-adherent composite resin combinations with or without application of an intermediate adhesive resin for TPH, CHA, Z250 used as substrate (base) composite. Different small superscript letters within each row and capital letters within each column indicates statistically significant differences $(p<0.05)$. For group abbreviations see Table 1.

\begin{tabular}{ccc}
\hline Substrate-Adherent & \multicolumn{2}{c}{$\begin{array}{c}\text { Intermediate adhesive resin (IAR) } \\
\text { without }\end{array}$} \\
TPH-TPH & $21.76 \pm 4.74^{\mathrm{a}, \mathrm{A}}$ & $35.19 \pm 6.85^{\mathrm{b}, \mathrm{A}}$ \\
TPH-CHA & $24.53 \pm 9.65^{\mathrm{a}, \mathrm{A}}$ & $31.15 \pm 8.72^{\mathrm{a}, \mathrm{A}}$ \\
TPH-Z250 & $6.01 \pm 2.39^{\mathrm{a}, \mathrm{B}}$ & $28.05 \pm 8.69^{\mathrm{b}, \mathrm{A}}$ \\
CHA-CHA & $34.97 \pm 3.17^{\mathrm{a}, \mathrm{A}}$ & $41.05 \pm 11.42^{\mathrm{a}, \mathrm{A}}$ \\
CHA-TPH & $18.37 \pm 9.45^{\mathrm{a}, \mathrm{B}}$ & $28.77 \pm 11.19^{\mathrm{a}, \mathrm{B}}$ \\
CHA-Z250 & $19.57 \pm 3.29^{\mathrm{a}, \mathrm{B}}$ & $29.15 \pm 4.92^{\mathrm{a}, \mathrm{A}, \mathrm{B}}$ \\
Z250-Z250 & $17.53 \pm 10.21^{\mathrm{a}, \mathrm{A}}$ & $41.55 \pm 11.01^{\mathrm{b}, \mathrm{A}}$ \\
Z250-CHA & $15.08 \pm 6.79^{\mathrm{a}, \mathrm{A}}$ & $38.44 \pm 11.74^{\mathrm{b}, \mathrm{A}, \mathrm{B}}$ \\
Z250-TPH & $16.72 \pm 9.14^{\mathrm{a}, \mathrm{A}}$ & $28.06 \pm 4.44^{\mathrm{a}, \mathrm{B}}$ \\
\hline
\end{tabular}




\section{Figures}

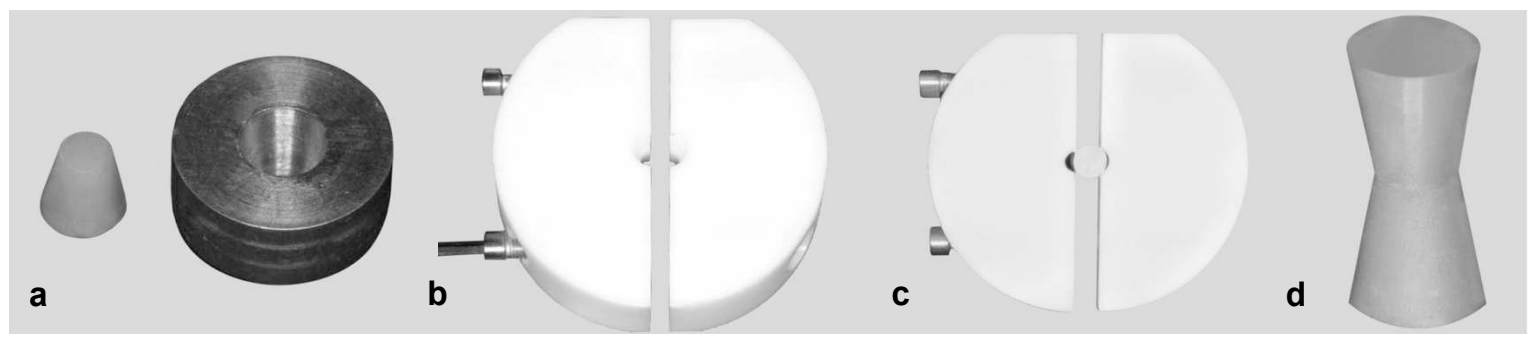

Figs. 1a-d Photos of a) machined brass ring used as metallic base for the fabrication of substrate composite, b) disc-shaped split polyethylene mold with a tapered orifice in its center used for the application of the adherent composite resins, c) two lateral screws joining the two portions of the split disc, d) hourglassshaped specimen obtained after removal of the polyethylene mold following photo-polymerization.

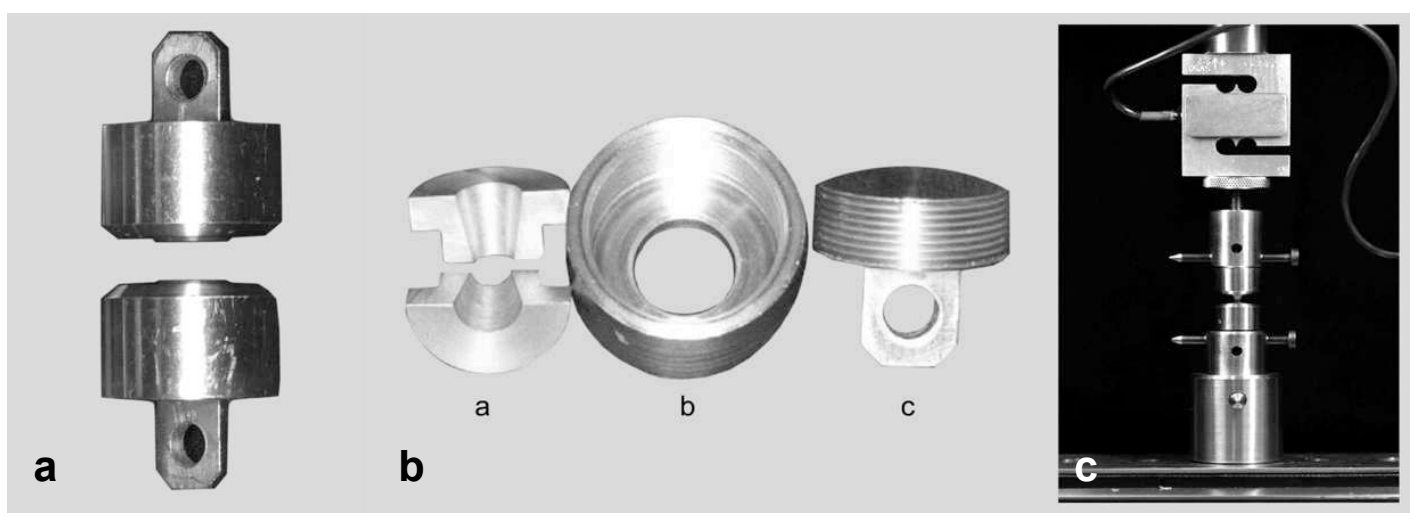

Figs. 2a-c Photos of a) two metal jigs with perforated rods fabricated to place the specimens in the Universal Testing Machine, b) disassembled metallic part showing tapered hemi sleeves, cylinder, perforated rod, c) specimen under tensile loading where the sleeves aligned in such a way that the adhesive interface remained perpendicular to the axis of applied force. 